\title{
A RELAÇÃO DA MÚSICA COM O DESENVOLVIMENTO PSICOMOTOR
}

\author{
THE RELATIONSHIP OF MUSIC WITH PSYCHOMOTOR DEVELOPMENT
}

\author{
Rosimeire Batista Sampaio Taborda ${ }^{1}$
}

Fabio José Antônio da silva²

\begin{abstract}
RESUMO: A psicomotricidade é uma área de estudo que trabalha estratégias que estimulam e desenvolvem a parte física-motora de um indivíduo através de sua interação com o ambiente, amplia o conhecimento e a consciência sobre movimentos, capacidades ou possibilidades, que serão aprimoradas por meio de estímulos. A relação da psicomotricidade com a música traz inúmeros benefícios na infância. O objetivo do presente trabalho visa compreender a contribuição da música e sua relação com a psicomotricidade, proporcionando uma reflexão sobre a interação da música no desenvolvimento psicomotor e suas contribuições para o desenvolvimento infantil. Para o desenvolvimento do tema foi realizado uma revisão de literatura disponíveis em periódicos e artigos online, que abordaram temas, conceitos, casos, estudos relevantes para fundamentar o presente trabalho. Com o desenvolvimento do artigo, espera-se perceber a música como um instrumento que estimule de forma significativa o amadurecimento e desenvolvimento de movimentos e habilidades físicas na criança.
\end{abstract}

Palavras-Chave: Música. Movimento. Aprendizagem. Infância.

ABSTRACT: Psychomotricity is an area of study that works strategies that stimulate and develop the physical-motor part of an individual through their interaction with the environment, increase knowledge and awareness about movements, capacities or possibilities, which will be enhanced through stimuli. . The relationship between psychomotricity and music has numerous benefits in childhood. The aim of this paper is to understand the contribution of music and its relationship with psychomotor, providing a reflection on the interaction of music in psychomotor development and its contributions to child development. For the development of the theme, a review of available literature in online journals and articles, which addressed relevant themes,

1 Graduação em Pedagogia Flated - Faculdade Latino-Americana de Educação. Pós-graduação em Psicopedagogia - FATEC. Pós-graduação em Psicomotricista - FATEC. Pós-graduação em TGD FATEC. Professora da Escola Adventista de Apucarana/PR.

2 Profissional de Educação Física. Mestre em Educação. Doutorando em Educação Física. CV:http://lattes.cnpq.br/3576574791707183. 
concepts, cases, studies to support the present work was performed. With the development of the article, it is expected to perceive music as an instrument that significantly stimulates the maturation and development of movements and physical abilities in children.

Keywords: Music. Movement. Learning. Childhood.

\section{INTRODUÇÃO}

A psicomotricidade é uma ciência que visa trabalhar estratégias que estimulam e desenvolvem a parte física-motora de um indivíduo, por meio de sua interação com o meio. A partir dessa relação, pode-se ampliar o conhecimento e a consciência sobre movimentos, capacidades ou possibilidades, que serão cada vez mais aprimoradas por meio de estímulos.

A música faz parte da vida de cada indivíduo, está presente em diferentes situações do dia-a-dia, e exerce uma influência significativa na vida do ser humano. Sua relação com a psicomotricidade tem sido vista de forma positiva, pois a música reflete aspectos do comportamento humano, e o contato com a música, desperta uma compreensão da composição e, consequentemente, influenciará no desenvolvimento de elementos que fazem parte da psicomotricidade.

A interação entre psicomotricidade e a música traz inúmeros benefícios ao indivíduo. $\mathrm{Na}$ fase da infância, onde todos os estímulos são essenciais para o desenvolvimento integral, essa relação é capaz de estimular a percepção auditiva, o movimento e percepção do corpo, o desenvolvimento da linguagem oral e corporal, amadurecimento físico e motor, e também reflete de forma significativa nos processos que englobam a aprendizagem. Atividades que são desenvolvidas com auxílio da música permitem que a criança desenvolva habilidades motoras, refletindo e controlando os movimentos com destreza e consciência corporal.

Por essas razões, a música possui papel relevante na psicomotricidade e no desenvolvimento integral da criança, sendo uma ferramenta de grande relevância, que contribui de forma significativa nas práticas pedagógicas. Dentro do contexto escolar, é importante que o educador oportunize momentos de desenvolvimento que sejam 
alegres e cheios de estímulos, para que a criança possa aprender e ampliar suas habilidades de interação, aprendizagem e desenvolvimento global.

Diante do que foi exposto, o trabalho intitulado "A relação da música com o desenvolvimento psicomotor”, se objetiva em estudar a temática, para melhor compreender a contribuição da música e sua relação com a psicomotricidade. $\mathrm{O}$ artigo proporcionará uma reflexão sobre a interação da música no desenvolvimento psicomotor e suas contribuições para o desenvolvimento infantil.

A escolha do tema será de grande relevância acadêmica e social, pois se justifica na importância de melhor compreender a relação da música no desenvolvimento motor. $\mathrm{O}$ artigo também se torna um elemento importante por se abordar um tema que auxilia o processo pedagógico, o qual deve ser norteado por práticas que visem estimular atividades que prepare, facilite e proporcione o desenvolvimento físico, motor, cognitivo e social do aluno. Sendo então considerada como uma ferramenta valiosa que deve ser inserida na psicomotricidade.

Para o desenvolvimento da temática, será realizado uma revisão de literatura disponíveis em periódicos e artigos online e disponíveis, os quais, abordam temas, conceitos, casos, estudos que serão relevantes para fundamentar o presente trabalho. Com o desenvolvimento do artigo, espera-se perceber a música como um instrumento que estimule de forma significativa o amadurecimento e desenvolvimento de movimentos e habilidades físicas na criança. Pois, quanto maior forem as experiências do educando, maiores serão suas conquistas em diferentes áreas de seu desenvolvimento.

\section{DESENVOLVIMENTO}

\section{A psicomotricidade e o desenvolvimento infantil}

A psicomotricidade pode ser definida como uma ciência que estuda o corpo em movimento e sua relação com o ambiente. Neste processo, está inserido aspectos orgânicos, sociais, afetivos, emocionais e cognitivos. E, portanto, engloba diferentes saberes e seu desenvolvimento abrange diferentes capacidades. 
De acordo com a Sociedade Brasileira de Psicomotricidade (2019) a psicomotricidade é uma área que estuda os movimentos corporais humanos dentro de seu contexto de interação social e ambiental. E, além disso busca fazer com que o sujeito, através de seus movimentos, se interaja com o espaço que está inserido e com meio social, sendo capaz de perceber e agir dentro de seu contexto. Santos (2016 p, 27) completa que a psicomotricidade é um

\footnotetext{
Processo que se inicia quando a vida começa, desde que o ser humano é gerado e tem a capacidade de se desenvolver fisicamente, é intrínseco a todo o ser humano. Dessa forma, é necessário que haja estímulos, para que a criança tenha oportunidade de crescer tornando-se num adulto independente, com capacidade para enfrentar o mundo que a rodeia (SANTOS, 2016, p. 27).
}

Sendo assim, pode-se dizer que está inserida desde os primeiros meses de vida e precisa ser estimulada para que o indivíduo consiga realizar todas as suas atividades de forma autônoma e satisfatória. Louro (2006) apud Costa (2015, p. II) diz que "a psicomotricidade é a relação entre os aspectos psicológicos, motores e cognitivos no desenvolvimento do ser humano desde a fecundação até o fim de sua vida".

A psicomotricidade é desenvolvida dentro das habilidades psicológicas, que compreende o querer fazer, habilidades cognitivas que consiste em saber fazer e habilidades físico-motoras que é o poder fazer. Todas essas etapas envolvem o conceito de psicomotricidade, o qual pode ser resumido como um desenvolvimento de aspectos psicológicos, cognitivos, emocional e físico, todos, relacionados de forma relevante com as fases do desenvolvimento humano (COSTA, 2015).

Dessa forma, ela tem grande contribuição no desenvolvimento humano, pois, "possibilita, a partir da vivência do corpo no espaço e no tempo, desenvolver a consciência de si mesmo como ser íntegro, capaz de sentir, expressar, compartilhar experiências e comunicar-se com os demais" (COSTA, 2015, p. I4). Assim, ela está atribuída em todas as atividades e ações do dia a dia de um indivíduo, o qual, por meio do movimento e de experiências, o ser desenvolve uma noção corporal, testa suas habilidades e domina seu corpo através de seus movimentos. (ALVES, 2012; COSTA, 2015). 
É oportuno mencionar que o ser humano é um ser em movimento, e que em diferentes fases da vida, inúmeras mudanças no desenvolvimento motor são observadas, e, ocorrem de forma gradual e contínua (JÚNIOR, 2019). Mas, durante a infância o desenvolvimento global da criança ocorre de forma mais intensificada, pois suas habilidades serão descobertas e aprimoradas na medida em que a criança vivência e experimenta o mundo ao seu redor (COSTA, 2015; JÚNIOR, 2019).

Assim, conforme a criança passa por cada fase do desenvolvimento, seus movimentos serão aprimorados e servirão de base para novas conquistas e habilidades, fazendo do desenvolvimento psicomotor um processo evolutivo. Além disso, e através do movimento corporal que a criança se expressa, estabelece interações sociais e com o espaço que a circunda, se conhece e compreende o mundo.

\begin{abstract}
As crianças têm um instrumento de total importância para comunicar-se com os adultos, esse instrumento é o corpo, pois é através dele com seus movimentos, gestos e expressões faciais que elas estabelecem sua comunicação, interagindo com o adulto sua forma de linguagem (FERREIRA E RUBIO, 2012, p. 5).
\end{abstract}

Diante dessas considerações é válido mencionar que para que a criança se desenvolva de forma plena e global, é preciso oportunizar experiências motivadoras, prazerosas e que estimulem a criança a participar desse processo de forma ativa. Sendo assim, atividades lúdicas, que sejam atrativas a cada faixa etária pode contribuir na aquisição de novas habilidades e conhecimento.

Por isso, é importante oferecer a criança um contato com o ambiente, onde ela seja capaz de interagir e realizar movimentos de manipulação, exploração, experimentação, locomoção, além de estímulos sensoriais necessários a um desenvolvimento sadio e que conduza a futuras capacidades. Ferreiro e Rubio (2012) ainda salientam que:

A criança em sua fase de crescimento, deve ter acesso a espaço e livre de intervenção adulta, para que a liberdade de ação corporal se desenvolva de maneira harmoniosa e venha contribuir para outras áreas de expansão, que estão ligadas a sua maturação, por exemplo, o desenvolvimento intelectual, em que a criança, livre na prática dos movimentos, torna-se criadora, inventando seu próprio mundo particular, e também no aspecto afetivo, na qual a criança aprende a lidar com suas emoções e frustrações, percebendo e 
aprendendo que ganhar e perder, faz parte da construção do ser (FERREIRA E RUBIO, 2012, p. 4).

O desenvolvimento da psicomotricidade é um assunto relevante e característico à infância, e, se dá através de estímulos e vivências corporais. A criança explora movimentos diversos, e por meio dessa, se adapta e adquiri novas habilidades e aprendizagens, construindo dessa forma seu conhecimento e participando de forma ativa do próprio aprendizado.

Portanto, a infância é caracterizada por um período de grande importância e sobre ela, deve-se conduzir um olhar criterioso e abrangente sobre as necessidades dessa etapa. E buscar propor situações que estas sejam atendidas, a ponto de que suas experiências lhes proporcionem o desenvolvimento de capacidades de ordem psicomotoras. E dessa forma, pode-se dizer que a psicomotricidade tem papel relevante no processo do desenvolvimento infantil.

\section{A relação da música com o desenvolvimento infantil}

A música está presente desde os primórdios da humanidade. Ela pode ser encontrada em diferentes contextos sociais e exerce grande influência no

comportamento das pessoas. É vista dentro de um contexto histórico cultural, refletindo aspectos da "cultura, expressão social ou de grupos, cultos e rituais religiosos, folclores e danças" (MACHADO et al, 2019, p.6). Além disso, a música pode ser percebida na natureza, também, através de instrumentos musicais e movimentos corporais.

Por meio dela, o ser experimenta um conjunto de sensações, as quais podem despertar sentimentos positivos, trazer tranquilidade, alegria, leveza, bem-estar, lembranças ou mesmo, tristeza, solidão e dentre outros. A música também atua como um meio de reflexão, conduzindo a pensamentos e ideais que são transmitidos por meio dela (FELICIANO, 2012).

Atualmente, é representada por uma variedade de ritmos, gêneros e estilos, que refletem a cultura de uma sociedade miscigenada e em constante transformação. 
A música é considerada como uma arte que tende a manifestar as diversas expressões humanas culturais presentes na sociedade (FELICIANO, 20I2).

Como dito, é uma arte presente desde a antiguidade, e acompanha todo o processo de desenvolvimento humano. Nos primeiros meses de vida a criança já tem contato com a música dentro do ambiente familiar, e isso, faz com que a criança cresça ouvindo e sendo estimulada de acordo com as preferências musicais do convívio familiar. E dessa forma, a criança manifesta sua interação com o mundo e com o ambiente que a cerca (FELICIANO, 2012; BRITO, 2003; MACHADO et al, 2019).

$\mathrm{Na}$ medida em que vai tendo contato com outros; amigos, escola e mídias, novos estilos serão apresentados, e estes, serão determinantes para a formação da personalidade, gosto musical, expressividade, aquisição de conhecimento e comunicação, além de aproximar e conhecer novas culturas. Brito (2003, p. 28) afirma que a música é representada "como uma das formas de representação simbólica do mundo, a música, em sua diversidade e riqueza, permite-nos conhecer melhor a nós mesmos e ao outro próximo ou distante”. O que torna a música um elemento essencial ao desenvolvimento humano, e, portanto, presente de forma intima no cotidiano das pessoas.

Em outro enfoque, é oportuno mencionar que as crianças aprendem e se desenvolvem em um espaço oportuno, motivador e desafiador. Ferreira e Rubio (2012, p. 7) citam que "a educação psicomotora deve ser trabalhada de maneira lúdica, divertida, animada e livre de regras e cobranças, porém com propostas devidas para que se alcance o objetivo desejado".

E neste sentido, a música atua como um instrumento que auxilia no processo do desenvolvimento infantil por despertar na criança interesse e divertimento na aprendizagem, além de permitir a aquisição de conhecimento e saberes através desse recurso. Machado et al (2019, p. 6) menciona que através da música "a criança manifestará sua relação com o mundo da mesma forma, e para isso, necessitará de um ambiente que colabore para a aprendizagem dessas significações, que são em sua maioria culturalmente construídas”. 
Diversas vertentes relacionadas à área da educação reconhecem o papel da música no desenvolvimento da criança em idade escolar, e, a forma de com ela atua na “formação e construção de um cidadão atuante e crítico na sociedade (FERREIRA E RUBIO, 20I2, p. 9)”. E ainda salientam que:

A música é uma das maneiras lúdica e divertida que pode e deve ser trabalhada na escola com os pequenos, a fascinação que a música exerce sobre a criança é visível, basta tocar um CD infantil, para que desperte nelas a alegria e a vontade de dançar, de cantar, desenvolvendo sua capacidade corporal, expandindo seus movimentos, percebendo seu espaço, sua delimitação, a percepção de si mesma e dos colegas (FERREIRA E RUBIO, 2012, p. 7).

Gomes (2008) apud Machado et al (2019, p, 8) fala que é a "arte dos sons que possui diversas propriedades capazes de estimular o desenvolvimento infantil, não só interferindo na percepção auditiva, mas também no movimento do corpo, na fala e no pensamento lógico e estético”. Ao contato com a música, a criança é capaz de percebe e assimilar o ritmo, incorporar e traduzir em movimentos, os quais serão determinantes para o processo do desenvolvimento psicomotor.

A música também permite um contato social e uma interação com o espaço, ou mesmo com elementos que fazem parte do contexto musical. Através dela, a criança se apropria de novos conhecimentos, experimenta sensações e descobre novas habilidades, se configurando com uma arte rica em possibilidades.

A música é uma linguagem tão rica em todos os aspectos, que desperta libertação na vida do ser humano, na liberdade de expressão, comunicação, socialização, na criação de algo novo, tornando-se um recurso forte na área educativa, no processo de desenvolvimento desde a sua existência, que é a infância, na sua primeira etapa de ensino e social: a Pré-Escola (FELICIANO, 2012, p. 25).

Diante do exposto, fica evidente a importância da música no desenvolvimento do indivíduo. Pois ela propicia um suporte para o desenvolvimento de forma lúdica, contextualizada e prazerosa de questões de ordem cognitiva, afetiva, psicomotora, social, oralidade, linguagem, emocional, cultural, comunicação e dentre outros elementos, que somados influenciam no desenvolvimento global do ser, destacando sua relevância no mundo infantil. 


\section{A psicomotricidade trabalhada através da música}

Muitos são os benefícios que a psicomotricidade desenvolve no sujeito. E quando aplicada de forma interessante, lúdica e prazerosa, traz avanços significativos no desenvolvimento psicomotor. Sabe-se que dentro da área educacional, é preciso buscar e introduzir instrumentos que tornem a prática pedagógica mais atraente ao público infantil e que propicie o processo de ensino e aprendizagem mais efetivos.

Partindo dessa consideração, a inserção da música em práticas de ensino, desenvolve inúmeras possibilidades de aquisição de conhecimento e desenvolvimento. Segundo Feliciano (2012) a música apresenta uma relação significativa com conteúdos, valores, expressividade, movimento e dentre outras situações.

Englobando todo esse contexto, a música torna-se meio para serem trabalhadas áreas diferenciadas de disciplinas no ambiente da educação infantil, como forma facilitadora para a aprendizagem de matemática, educação física e outras, pois essa interação de áreas é indiscutível na educação infantil, faz parte do meio lúdico, da integração para o ensino e aprendizagem da criança nesta etapa (FELICIANO, 2012, p. 27).

É oportuno mencionar que a relação da música com a psicomotricidade, estimula e possibilita, de forma natural e espontânea, o desenvolvimento psicomotor.

Ao inserir músicas para realizar movimentos, a criança explora ritmo, lateralidade, noção espacial, se expressa de forma livre, articula ações sequenciais,

\footnotetext{
Criam-se movimentos e expressões ao ouvir uma música espontaneamente, no bater os pés, as mãos, ao querer batucar algo, ou no balançar do corpo conforme o ritmo. Nas crianças, essa naturalidade ainda é mais forte, ela movimenta o corpo, cria sua dança e, ao cantar, cria expressões faciais encantadoras, mostrando realmente o sentimento de alegria (FELICIANO, 2012, p. 27).
}

Ao introduzir meios que emitem som ou música, a criança explora, imita, reproduz movimentos, respondem conforme o ritmo e/ou expressividade, criam e recriam movimentos ao estímulo musical. Feliciano (2012) menciona que músicas mais atrativas, conduzem a movimentos mais elaborados e atrativos. Estimulando a coordenação motora, sabendo identificar partes do corpo, representar e identificar sons e ritmos da natureza. 
É válido mencionar que músicas que contenham elementos que fazem da vida da criança, tende a despertar ainda mais o interesse na participação e interação da aprendizagem por meio da música. O ritmo, letra e som são determinantes para colocar a criança em contato com essa arte, bem como desenvolve inúmeros aspectos psicomotores, e estes serão essenciais para a aquisição da leitura, escrita, compreensão de mundo, do espaço e tempo (FELICIANO, 2012; MACHADO et al, 2019).

Machado et al (2019) afirmam que "a música traz em si elementos que auxiliam nas atividades psicomotoras e no desenvolvimento infantil". Esses elementos tende a preparar a criança a desempenhar outras funções e descobrir novas possibilidades e capacidades. Essa associação, reflete também na linguagem oral e corporal, no pensamento lógico, na fantasia e criatividade.

Diante desse aspecto, é interessante mencionar que a música contém atributos que desenvolve o cognitivo, o psicomotor e afetividade devido os elementos que a compõem, dentre eles destaca-se o timbre, melodia, letra, ritmo, harmonia, duração, altura, intensidade e outros. Por isso, dentro do contexto de educação musical pode ser dividida em duas categorias, sendo a "Educação do Senso Músico-Rítmico e Educação do Ouvido Musical” (MÁRSICO, 2003 apud MACHADO et al, 2019, p. 7).

Essa educação musical é desenvolvida dentro de três níveis de aprendizagem musical. O primeiro consiste na percepção musical, no qual ocorre um desenvolvimento e sensibilização do órgão auditivo em resposta ao contato com sons, refletindo em reações diversas por meio do contato com a música. Já o segundo nível, é caracterizado pela percepção do ritmo e da melodia.

Neste nível, a criança é estimulada a perceber esses elementos em contextos musicais, e desenvolve condições de reproduzir e identificar partes da melodia e reconhecer ou associar em outras situações. Por fim, o terceiro nível é identificado através do desenvolvimento da percepção harmônica e polifônica. Neste. A criança já é capaz de descobrir e perceber os diferentes sons de uma composição, acompanhando a música com agilidade, mobilidade, amplitude e consciência sonora (ZAMPRONHA, 2007, apud, MACHADO et al, 2019). 
Diante dessas propriedades que a educação musical proporciona a criança, nota-se o quanto a inserção da música no mundo infantil auxilia no desenvolvimento dos atributos supracitados. E, quando associada à psicomotricidade, traz inúmeros outros benefícios significativos ao desenvolvimento psicomotor. Machado et al (2019, p. 7) afirma que "ao aprofundar-se na aprendizagem musical, a criança agrega conhecimentos sobre as partes constituintes da música e desenvolve aspectos presentes na psicomotricidade".

Por essas razões a música e o movimento estão intimamente relacionados e atuam de forma relevante no processo de aquisição de conhecimentos e no desenvolvimento psicomotor da criança (FELICIANO, 20I2; MACHADO et al, 2019).

\section{CONSIDERAÇÕES FINAIS}

Através do desenvolvimento desse artigo, pode-se perceber o quanto a psicomotricidade tem grande influência no desenvolvimento da criança, tanto no aspecto psicomotor como também na aprendizagem. E quando a psicomotricidade é associada a música estimula ainda mais essas aquisições, proporcionando um crescimento com mais intensidade, tornando-se também bem mais atrativa $e$ significativa para a criança.

Isso porque a música é um elemento que faz parte da vida humana, sendo caracterizada como uma manifestação da própria cultura, e, portanto, parte do cotidiano de qualquer ser humano. Com a música a criança é capaz de se expressar de forma interna e externa, de aprender a se comunicar por meio da linguagem oral e corporal, de expressar seus sentimentos e percepções em relação ao mundo, de conhecer e socializar com o mundo, com pessoas e com culturas distintas.

E por isso, a introdução da música em atividades de psicomotricidade propicia um desenvolvimento amplo. Contribuindo de forma significativa na formação e desenvolvimento de habilidades motoras, aumentando o domínio de capacidades diversas, além de buscar desenvolver na criança uma consciência corporal. 
Diante do que foi exposto, fica claro a importância do meio escolar e o papel do educador em desenvolver estratégias que englobe a música em sua prática pedagógica, a fim de intervir de forma significativa e prazerosa no desenvolvimento motor. Possibilitando um desenvolvimento da criança, nos aspectos cognitivos, sensorial, motor, social, emocional e afetivo por meio de atividades que relacionem a psicomotricidade e a música.

\section{REFERÊNCIAS}

ALVES, Fátima. Psicomotricidade: corpo, ação e emoção. Rio de Janeiro: Wak, 2012.

ASSOCIAÇÃO BRASILEIRA DE PSICOMOTRICIDADE. A Psicomotricidade. Rio de Janeiro. Disponível em: www.psicomotricidade.com.br/apsicomotricidade.htm. Acesso em: 27 de outubro de 2019.

BRITO, TECA ALENCAR DE. Música na Educação Infantil- Propostas para a Formação Integral da Criança. São Paulo, Peirópolis, 2003.

COSTA, J. L. V. A música no desenvolvimento motor da criança na educação infantil. Trabalho de Conclusão de Curso em Pedagogia pela Universidade de Sorocaba. Sorocaba, São Paulo, 2015.

FAZAN, F. H.; FARIA, V. A. M. A música e a psicomotricidade na educação infantil. Revista Funec Científica - Educação. Santa Fé do Sul. v. 2, n. 4, 2016.

FELICIANO, S. A. A música na Educação Infantil. Trabalho de Conclusão de Curso em Pedagogia Pelo Centro Universitário Católico Salesiano Auxilium. Lins, São Paulo, 2012.

FERREIRA, L. A.; RUBIO, J. A. S. A contribuição da música no desenvolvimento da psicomotricidade. Revista Eletrônica Saberes da Educação. v.3, n.ı, 2012.

GODOI, L. R. A importância da música na educação infantil. Trabalho de Conclusão de Curso em Pedagogia pela Universidade Estadual de Londrina. Londrina, Paraná, 2011 .

JÚNIOR, P. F. L. Desenvolvimento motor infantil por meio de atividades lúdicas em um colégio particular do município de Guarapuava - Pr. In: XIII Congresso Nacional de Educação - EDUCERE. 
MACHADO, B.; BATISTA, D. V. A.; SIMÕES, A. S. Psicomotricidade e música: uma implementação do componente curricular na educação infantil. Faculdade Integrada INESUL.

NOGUEIRA, M. A. A música e o desenvolvimento da criança. Disponível em http://www.educadores.diaadia.pr.gov.br/arquivos/File/2010/artigos_teses/20II/Art e/Artigos/moniqueartigo.pdf.

RABELO, K. I. L.; AQUINO, G. B. Relação entre psicomotricidade e desenvolvimento infantil: um relato de experiência. Revista Científica de Faminas. v. Io, n. 3, 20I4.

REIS, A. R. G.; REZENDE, U. B.; RIBEIRO, M. P. P. F. A música e o desenvolvimento infantil: o papel da escola e do educador. Revista Eletrônica da Faculdade Metodista Granbery. n.12, 2012.

SANTOS, M. J. G. L. A influência da música no desenvolvimento motor. Trabalho de Conclusão de Curso em Docência na Educação Pré-Escolar pelo Instituto Superior de Educação e Ciências. 2016. 